\title{
Prenatal sonographic diagnosis of fetal valproate syndrome: a case report
}

\author{
Norihiko Kikuchi, Satoshi Ohira*, Ryoichi Asaka, Kyoko Tanaka, Akiko Takatsu and Tanri Shiozawa
}

\begin{abstract}
Background: Prenatal exposure of mother to valproate (VPA) causes teratogenic effects in the fetus, namely fetal valproate syndrome (FVS). We report a case of fetal valproate syndrome rarely diagnosed by prenatal sonographic examination.

Case presentation: Our patient was a female infant who was born to a 27-year-old nulliparous Japanese woman with epilepsy. The mother was diagnosed with infantile epilepsy at 1 year of age and had been using three antiepileptic drugs, including valproate, but preconceptional counseling was not performed. At 25 weeks of gestation, contracture of the fetal right wrist joint suggestive of a radial ray defect was observed by transabdominal ultrasonography. The fetus demonstrated growth retardation starting from 32 weeks of gestation. In addition, saddle nose as a facial anomaly was detected by three-dimensional ultrasound at 37 weeks of gestation. Accordingly, we suspected that the fetus had fetal valproate syndrome. At 39 weeks of gestation, the mother delivered an infant weighing $2056 \mathrm{~g}$. The neonate had characteristic features of fetal valproate syndrome, such as facial configuration, slight muscular hypotonia of the whole body, breathing problems, right-hand articular contracture accompanied by radial ray defect, and cardiovascular malformation.

Conclusions: When obstetricians manage epileptic pregnant women without enough preconceptional counseling or adjustment for antiepileptic drugs, careful sonographic observation of the fetus is mandatory.
\end{abstract}

Keywords: Epilepsy, Fetal valproate syndrome, Prenatal diagnosis, Ultrasonography, Preconceptional counseling

\section{Background}

Valproate (VPA) is used for the treatment of epilepsy and mood disorders [1]. Prenatal exposure of the mother to VPA causes teratogenic effects in the fetus, namely fetal valproate syndrome (FVS). FVS is characterized by a number of abnormalities, including neural tube defects; congenital heart defects; limb defects; genitourinary defects; brain, eye, and respiratory anomalies; and abdominal wall defects [2]. Although FVS is well-known as a newborn disease, reports of prenatal ultrasonographic diagnosis are limited, and only two cases have been reported in the English-language literature. We report another case of FVS diagnosed by prenatal ultrasonography. Careful ultrasonographic observation might be useful for predicting FVS in pregnant women using antiepileptic drugs, including high-dose VPA, without enough preconceptional counseling.

\footnotetext{
* Correspondence: osatoshi@shinshu-u.ac.jp

Department of Obstetrics and Gynecology, Shinshu University School of Medicine, 3-1-1 Asahi, Matsumoto 390-8621, Japan
}

\section{Case presentation}

Our patient was a female infant who was born to a 27-year-old Japanese nulliparous woman. The mother had been diagnosed with infantile epilepsy at 1 year of age. Her antiepileptic therapy was discontinued at the age of 7 years because she had no symptoms, but she had an epileptic seizure at the age of 17 years, and treatment with the antiepileptic drugs was resumed. She married at the age of 25 years; however, she did not receive preconceptional consultation. Because she had slight mental retardation, she did not report her wish for a pregnancy to her physician. At the age of 27 years, she was referred to our hospital from a primary obstetrical clinic at 13 weeks of gestation. She was obese, with a body mass index of $30 \mathrm{~kg} / \mathrm{m}^{2}$. The antiepileptic drugs she was taking included $1400 \mathrm{mg} /$ day of VPA, $140 \mathrm{mg} /$ day of phenobarbital (PB), and $1200 \mathrm{mg} /$ day of carbamazepine (CBZ). The blood concentrations of the drugs were $80 \mu \mathrm{g} / \mathrm{ml}$ VPA (effective blood range is from 40 to $100 \mu \mathrm{g} / \mathrm{ml}), 26.1 \mu \mathrm{g} / \mathrm{ml} \mathrm{PB}(10-30 \mu \mathrm{g} / \mathrm{ml})$, and $10.5 \mu \mathrm{g} / \mathrm{ml}$ 
CBZ (4-12 $\mu \mathrm{g} / \mathrm{ml})$. Despite the mother's use of three antiepileptic drugs, she had convulsions about three times per week. Therefore, reduction or alteration of the drugs was difficult. She was informed of her epileptic status and the teratogenic effects of VPA, but her wish to have a baby was so strong that she continued her pregnancy with oral folic acid of $5 \mathrm{mg} /$ day.

Although second-trimester transabdominal ultrasonography was performed at 20 weeks of gestation, fetal malformation was not detected because of a poor ultrasound image due to maternal obesity. At 25 weeks of gestation, contracture of the fetal right wrist joint suggestive of a radial ray defect was detected by ultrasonography (Fig. 1a, b). The fetus demonstrated growth retardation starting from 32 weeks of gestation. After that, fetal ultrasonography was performed weekly until delivery. At 34 weeks of gestation, the estimated fetal weight was $1660 \mathrm{~g}$ (-2.5 SD: standard deviation), the biparietal diameter was $74.9 \mathrm{~mm}(-2.8 \mathrm{SD})$, mother's abdominal circumference was $261.7 \mathrm{~mm}(-1.5 \mathrm{SD})$, and the femur length was $58 \mathrm{~mm}(-1.3 \mathrm{SD})$. The right ulna was shorter than the left ulna; the right was $35 \mathrm{~mm}$ (-8.4 SD), and the left was $53 \mathrm{~mm}(-1.1 \mathrm{SD})$. The right radial ray was not detected. At 37 weeks of gestation, saddle nose as a facial anomaly was observed on a three-dimensional ultrasound (Fig. 1c). Therefore, right radial ray defect and saddle nose caused by FVS were suspected.
The serum levels of antiepileptic drugs were within effective ranges; however, multiple syncopes occurred. Fetal growth retardation was not improved, but growth arrest was not observed. The mother went into active labor at 39 weeks and 2 days of gestation and delivered a female infant weighing $2056 \mathrm{~g}$ with Apgar scores of 8 and 8 at 1 and 5 minutes, respectively. The neonate showed slight muscular hypotonia of the whole body and respiratory distress. The neonate's physical examination revealed bend and contracture of the right wrist joint (Fig. 2a), right radial ray defect (Fig. 2b), a ventricular septal defect (VSD), an atrial septal defect (ASD), and a patent ductus arteriosus (PDA) in addition to characteristic facial configurations such as euryopia, broad nasal root, saddle nose, shallow philtrum, and low-set ears. The neonate's features were compatible with FVS. PDA ligation was performed when she was 13 days old, and cast immobilization of the right forward arm was started when she was 89 days old. A follow-up examination at age 12 months demonstrated developmental and growth retardation.

\section{Discussion}

The recommended treatment for a woman with epilepsy who wishes to have children is to use a single drug or newer antiepileptic drugs such as lamotrigine or levetiracetam [3-5]. Although avoidance of VPA is an option
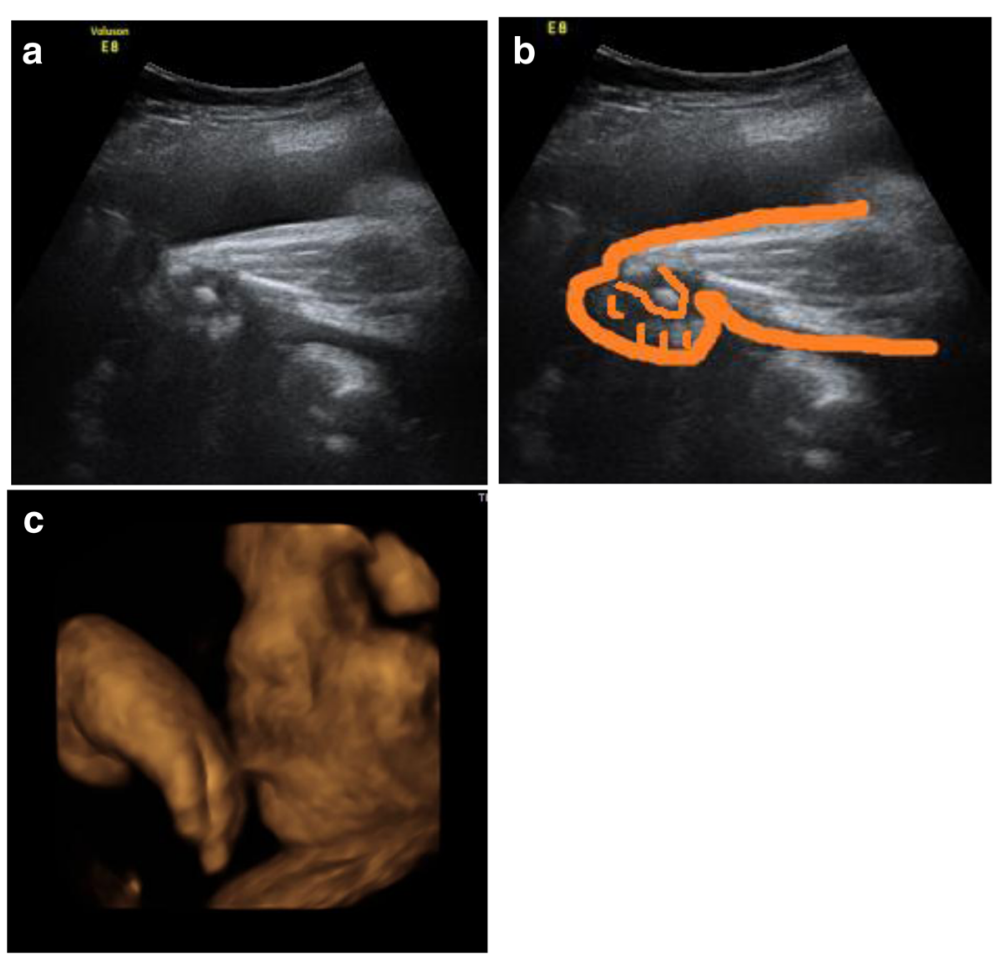

Fig. 1 Prenatal ultrasonographic image. a Contracture of the fetal right wrist joint is observed at 25 weeks of gestation. $\mathbf{b}$ Schematic image of the right wrist joint. c Saddle nose as a facial anomaly is observed on this three-dimensional ultrasound obtained at 37 weeks of gestation 

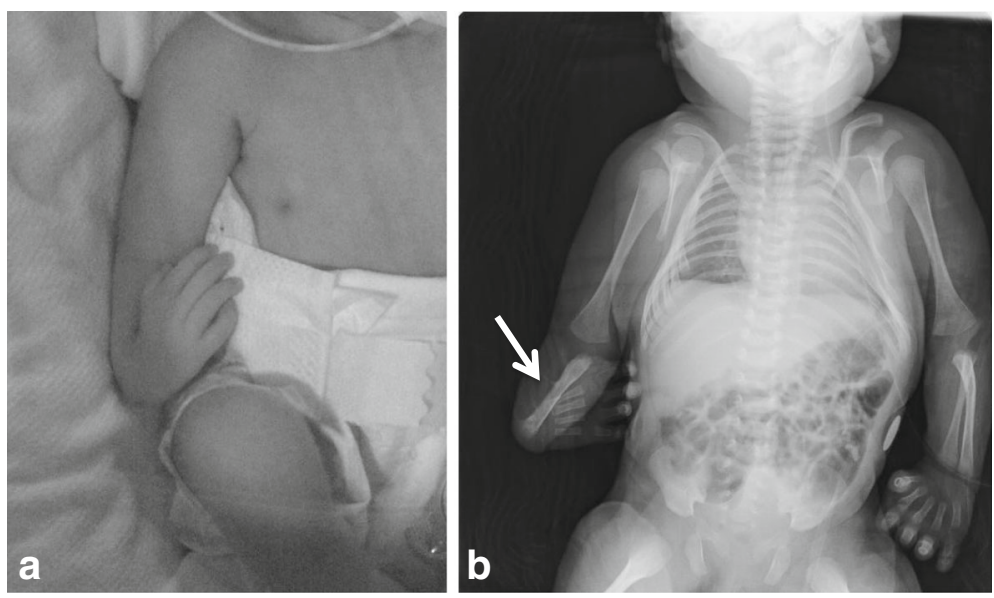

Fig. 2 a The neonate's physical examination reveal bend and contracture of right wrist joint. b A right radial ray defect is observed on this $x$-ray (arrow)

to prevent FVS, there are cases where the control of convulsions is impossible without VPA. There is a doseeffect relationship between fetal malformations and VPA exposure during the first trimester of pregnancy; that is, higher VPA doses are associated with a significantly greater risk than lower doses. Several investigators have reported a higher fetal malformation risk with maternal VPA doses above $1000 \mathrm{mg} /$ day or high blood concentrations above $70 \mu \mathrm{g} / \mathrm{ml}$ during pregnancy [6]. Combined use of antiepileptic drugs is also associated with a high risk of fetal malformations. The risk of major congenital malformations is influenced not only by the type of antiepileptic drug used but also by dose and other variables, which should be taken into account in the management of epilepsy in women of childbearing potential [4]. Thus, preconceptional counseling for a woman with epilepsy who is taking antiepileptic drugs is very important.

When a woman who is being treated with antiepileptic drugs, including VPA conceives, careful ultrasonographic observation of the fetus might be useful for predicting FVS. Witters et al. reported that prenatal nuchal edema could be the first presenting sign of FVS [7]. Because infants with FVS sometimes have multiple congenital heart diseases, this finding is reasonable and useful for predicting FVS. Contrary to our prediction, most reports of FVS have occurred in neonates and children, and we found only two reports that provided prenatal sonographic representations of FVS [7, 8] (Table 1). Witters et al. [7] reported an ultrasonographic feature of a fetal flat nasal bridge with a short nose at 21 weeks of gestation. The following pregnancy course was uneventful in their case, and the baby was born at term. The infant also had dysmorphic features seen in FVS: a long philtrum, thin upper lip, and long toes with a short fifth toe [7]. Kennelly and Moran [8] described a radial ray defect visualized by two- and three-dimensional prenatal ultrasonography at 19 weeks of gestation. The pregnancy was terminated, and the baby was revealed to have aortic valve stenosis postnatally [8]. In our case, contracture of the fetal wrist joint suggestive of a radial ray defect and saddle nose as a facial anomaly were detected by prenatal ultrasonography, indicating that the detection of these findings is a hallmark for precise prenatal diagnosis of FVS. In addition, the present case is the first

Table 1 Reported cases of fetal valproate syndrome detected by prenatal ultrasonography

\begin{tabular}{|c|c|c|c|c|c|}
\hline Author & $\begin{array}{l}\text { Maternal } \\
\text { age }\end{array}$ & $\begin{array}{l}\text { Antiepileptic } \\
\text { drugs }\end{array}$ & $\begin{array}{l}\text { US findings of fetus } \\
\text { (gestational weeks) }\end{array}$ & Delivery & Additional postnatal findings \\
\hline Witters et al. 2002 [7] & 40 years & VPA; 1000 mg/day & $\begin{array}{l}\text { Flat nasal bridge with } \\
\text { short nose ( } 21 \text { weeks) }\end{array}$ & Term-delivery female & Long philtrum, thin upper lip, long toes \\
\hline $\begin{array}{l}\text { Kennelly and Moran } \\
2007 \text { [8] }\end{array}$ & N/A & VPA; dose N/A & $\begin{array}{l}\text { Bilateral radial ray } \\
\text { defects (19 weeks) }\end{array}$ & Termination of pregnancy & Aortic valve stenosis \\
\hline \multirow[t]{2}{*}{ Our case } & 27 years & $\begin{array}{l}\text { VPA } 1400 \text { mg/day } \\
\text { PB } 140 \mathrm{mg} / \text { day } \\
\text { CBZ } 1200 \mathrm{mg} / \text { day }\end{array}$ & $\begin{array}{l}\text { Contracture of right } \\
\text { wrist joint suggestive } \\
\text { of radial ray defect } \\
\text { ( } 25 \text { weeks) }\end{array}$ & Term-delivery female & VSD, ASD, PDA; shallow philtrum; euryopia \\
\hline & & & Saddle nose (37 weeks) & & \\
\hline
\end{tabular}


case of FVS in which both contracture of the wrist joint and saddle nose were observed prenatally. In our case, fetal cardiac malformation, including ASD and VSD, was not detected prenatally because of a poor ultrasound image due to maternal obesity.

When radial ray defects and facial anomaly are observed by prenatal ultrasonography, differential diagnoses of FVS are trisomy 18, trisomy 13, Cornelia de Lange syndrome, Roberts syndrome, acrofacial dysostosis, BallerGerold syndrome, Fanconi anemia, Aase syndrome, thrombocytopenia-absent radius (TAR) syndrome, and Holt-Oram syndrome [8]. The facial anomaly in FVS is usually flat nasal bridge or saddle nose; facial anomalies seen in other syndromic disorders are micrognathia (trisomy 18, Cornelia de Lange syndrome, acrofacial dysostosis, Baller-Gerold syndrome, and TAR (thrombocytopenia with absent radius) syndrome, cleft lip and/or palate (trisomy 13, Roberts syndrome, and Aase syndrome), mandibular protrusion (Cornelia de Lange syndrome), microphthalmus (Fanconi anemia), and hypertelorism (Holt-Oram syndrome) [8]. VACTERL association (vertebral anomalies, anal atresia, cardiovascular anomalies, tracheoesophageal fistula, esophageal atresia, renal (kidney) and/or radial anomalies, limb defects) is associated with radial ray defects, but it is not usually accompanied by facial anomaly [8]. Although Binder syndrome is characterized by a flat midface and nasal hypoplasia, it is not usually accompanied by radial ray defects [9].

\section{Conclusions}

The present case indicated the possibility of prenatal diagnosis of FVS using ultrasonography. Especially, detection of contracture of the fetal wrist joint and saddle nose seemed to have diagnostic value. When obstetricians manage women with epilepsy using epileptic drugs without preconceptional counseling, meticulous ultrasonographic observation should be performed to prevent serious morbidity and mortality in postnatal life. Furthermore, when multiple malformations to an extensive degree exist, early prenatal diagnosis may lead to more appropriate management of FVS, including termination of pregnancy and providing counseling for future pregnancies.

\section{Acknowledgements}

The authors are grateful to Yukihide Miyosawa (Department of Pediatrics, Shinshu University School of Medicine) for examination and treatment of the neonate.

\section{Funding}

Not applicable.

Availability of data and materials Not applicable.
Authors' contributions

NK, RA, KT, and AT performed fetal ultrasonography during the mother's pregnancy. SO and TS helped to draft the manuscript. All authors read and approved the final manuscript.

\section{Competing interests}

The authors declare that they have no competing interests.

\section{Consent for publication}

Written informed consent was obtained from the patient's legal guardian for publication of this case report and any accompanying images. A copy of the written consent is available for review by the Editor-in-Chief of this journal. We gave attention to privacy protection in accordance with ethics committee guidelines.

Received: 23 January 2016 Accepted: 10 October 2016

Published online: 03 November 2016

\section{References}

1. Genton P, Semah F, Trinka E. Valproic acid in epilepsy: pregnancy-related issues. Drug Saf. 2006;29:1-21.

2. Clayton-Smith J, Donnai D. Fetal valproate syndrome. J Med Genet. 1995;32:724-7.

3. Juárez-Olquín H, Belmont-Gómez A, Flores-Pérez J, Barranco-Garduño LM, Flores- Pérez C. Malformations in newborns associated to anticonvulsant consumption during pregnancy: experience in third level hospital of Mexico. Rev Invest Clin. 2008;60:15-20.

4. Tomson T, Battino D, Bonizzoni E, Craig J, Lindhout D, Sabers A, et al. Dose-dependent risk of malformations with antiepileptic drugs: an analysis of data from the EURAP epilepsy and pregnancy registry. Lancet Neurol. 2011;10:609-17.

5. Mawhinney E, Craig J, Morrow J, Russell A, Smithson WH, Parsons L, et al. Levetriacetam in pregnancy: results from the UK and Ireland epilepsy and pregnancy registers. Neurology. 2013;80:400-5.

6. Kaneko S, Battino D, Andermann E, Wada K, Kan R, Takeda A, et al. Congenital malformations due to antiepileptic drugs. Epilepsy Res. 1999:33:145-58.

7. Witters I, Van Assche F, Fryns JP. Nuchal edema as the first sign of fetal valproate syndrome. Prenat Diagn. 2002;22:834-5.

8. Kennelly MM, Moran P. A clinical algorithm of prenatal diagnosis of radial ray defects with two and three dimensional ultrasound. Prenat Diagn. 2007; 27:730-7.

9. Cook K, Prefumo F, Presti F, Homfray T, Campbell S. The prenatal diagnosis of Binder syndrome before 24 weeks of gestation: case report. Ultrasound Obstet Gynecol. 2000;16:578-81.

Submit your next manuscript to BioMed Central and we will help you at every step:

- We accept pre-submission inquiries

- Our selector tool helps you to find the most relevant journal

- We provide round the clock customer support

- Convenient online submission

- Thorough peer review

- Inclusion in PubMed and all major indexing services

- Maximum visibility for your research 